\title{
Tobacco Research Implementation Group
}

National Cancer Institute

\section{Source}

National Cancer Institute. Tobacco Research Implementation Group. NCI Thesaurus.

Code C19668.

Created to establish $\mathrm{NCl}$ 's tobacco-related cancer research priorities for the next five to seven years. The first initiative of the group creates a collaborative Transdisciplinary

Tobacco Research Centers program. The second program funds state and community tobacco control intervention research. 